\title{
Repression of the expression of TET2 by ZEB1 contributes to invasion and growth in glioma cells
}

\author{
BO CHEN $^{1 *}$, YANQING LEI $^{2 *}$, HONGQUAN WANG $^{1}$, YANWEI DANG $^{1}$, \\ PEIHAI FANG ${ }^{1}$, JUN WANG ${ }^{1}$, JINBO YANG ${ }^{1}$ and LIJUN LIU ${ }^{1}$ \\ Departments of ${ }^{1}$ Neurosurgery and ${ }^{2}$ Emergency, Xiangyang No. 1 People's Hospital, \\ Hubei University of Medicine, Xiangyang, Hubei 441000, P.R. China
}

Received January 8, 2016; Accepted March 9, 2016

DOI: $10.3892 / \mathrm{mmr} .2017 .6288$

\begin{abstract}
Malignant gliomas are the most common and aggressive type of brain tumor. The suppressive role of ten-eleven translocation 2 (TET2) has been implicated in certain types of cancer, however, its role in gliomas remains to be elucidated. The present study aimed to determine the expression pattern and biological role of TET2 in glioma, using RT-qPCR and immunohistochemistry, and its results indicated that the expression of TET2 was frequently decreased in gliomas and that repression of the expression of TET2 correlated with the progression of glioma. The ectopic expression of TET2 inhibited the invasive potential of glioma cells, and inhibited glioma cell proliferation in vitro and growth in vivo. Additionally, the expression of Zinc finger E-box-binding homeobox 1 (ZEB1) was increased in gliomas and was positively correlated with progression, but inversely correlated with the expression of TET2. ZEB1 was also confirmed to physically bind to the TET2 promoter. ZEB1 knockdown resulted in an increase in the expression of TET2 and elevation of TET2 promoter activity in glioma cells. These findings indicated that the downregulation of TET2 by ZEB1 is a critical oncogenic event in gliomas.
\end{abstract}

\section{Introduction}

Malignant gliomas are the most common and most aggressive type of malignant primary brain tumor in humans (1). They are characterized by high proliferation, migration and invasion abilities. World Health Organization grade IV astrocytomas are known as glioblastoma multiforme (GBM). The majority of GBMs arise de novo and are defined as primary GBMs,

Correspondence to: Dr Lijun Liu, Department of Neurosurgery, Xiangyang No. 1 People's Hospital, Hubei University of Medicine, 15 Jiefang Road, Xiangyang, Hubei 441000, P.R. China

E-mail: lijunliuxy@126.com

*Contributed equally

Key words: glioma, ten-eleven translocation 2, cancer progression, zinc finger E-box-binding homeobox 1 whereas progression from lower grade astrocytomas results in secondary GBMs (1). Despite aggressive surgery combined with radiation, chemotherapy and biological therapy, the prognosis of patients remains poor, with a 5-year survival rate of $4-5 \%$ and a median survival rate of $\sim 14$ months $(2,3)$. This poor prognosis is considered to be primarily a result of the invasive pattern of tumor growth, which precludes complete resection and enhances resistance to therapies (4). Thus, elucidation of the molecular mechanisms underlying the progression of malignant gliomas is urgently required.

The ten-eleven translocation (TET) family of proteins is composed of three members, TET1, TET2 and TET3. They share a conserved Cys-rich domain and double-stranded $\beta$ helix domain (5). TETs exhibit their unique enzymatic function and facilitate DNA demethylation, oxidizing 5-methylcytosine $(5 \mathrm{mC})$ to 5 -hydroxymethylcytosine $(5 \mathrm{hmC}), 5$-formylcytosine (5fC) and 5-carboxylcytosine $(5 \mathrm{caC})$ in a stepwise manner $(6,7)$. TETs can thus act as epigenetic regulators, and can modulate gene transcription and cellular functions (8). Genetic investigations in mutant mice have linked the function of Tet genes to various biological pathways, including zygotic, embryonic and perinatal development (9); self-renewal, proliferation and differentiation of hematopoietic stem/progenitor cells (10); and induction of pluripotent stem cell reprogramming (11). Pathologically, mutations and/or deletions of the TET2 gene have been reported to frequently occur in hematopoietic malignancies $(12,13)$. Loss of the expression of TET2 confers to the development and progression of hematopoietic malignancies, including acute myeloid leukemia (14) and B cell malignances (15). Additionally, androgen hormones involved in the progression of prostate cancer repress TET2. The repression of TET2 activates key prostate cancer-associated pathways, including mammalian target of rapamycin (16). Previously, TET1, 2 and 3 have been reported to be abundant in the brain, and the level of TET2 in particular is steadily sustained in central nervous system development (17). The functional perturbation of TET2 and TET3 leads to defects in neuronal differentiation (18). The involvement of TET2 in gliomas remains to be fully elucidated. The present study aimed to explore the expression pattern, the biological role and the mechanisms for dysregulation of TET2 and revealed that TET2 was downregulated and associated with progression in gliomas. Overexpressed TET2 inhibited glioma cell 
proliferation and invasion. It was also demonstrated that the overexpression of zinc finger E-box-binding homeobox 1 (ZEB1) repressed the expression of TET2 in glioma cells.

\section{Materials and methods}

Clinical specimens, cell culture and transfection. A total of 42 paired fresh glioma tissues and adjacent non-tumor tissues were collected between May 2013 and July 2014, and 96 formalin-fixed paraffin-embedded glioma tissues were collected between June 2007 and October 2010, at Xiangyang No. 1 People's Hospital (Hubei, China). The fresh tissue samples were immediately snap-frozen in liquid nitrogen and were used for RNA extraction. Each of the patients provided written informed consent and the present study was approved by ethics committee of Xiangyang No. 1 People's Hospital. A172, SW1088, U118MG, U87MG and U251MG human glioma cell lines were obtained from American Type Culture Collection (Manassas, VA, USA) and maintained at $37^{\circ} \mathrm{C}$ in a humidified atmosphere containing $5 \% \mathrm{CO}_{2}$ The cells were cultured in DMEM supplemented with $10 \%$ fetal bovine serum (Gibco; Thermo Fisher Scientific, Inc., Waltham, MA, USA). For TET2 overexpression and ZEB1 knockdown, the cells were transfected with the TET2-overexpressing vector, pcDNA3.1-TET2, or with the pSUPER vector containing ZEB1-specific short hairpin (sh)RNAs, respectively (Guangzhou Fulengen Co., Ltd., Guangzhou, China). Transfection was performed using Lipofectamine 2000 (Invitrogen; Thermo Fisher Scientific, Inc.) in accordance with the manufacturer's protocol.

Reverse transcription-quantitative polymerase chain reaction (RT-qPCR) analysis of $m R N A$. Tissues were excised and homogenized under liquid nitrogen. Total RNA from the cells and tumor tissues were extracted using TRIzol reagent, and $2 \mu \mathrm{g}$ mRNAs was used to synthesize cDNAs using the Super-Script first-strand synthesis system (Thermo Fisher Scientific, Inc.); $1 \mu \mathrm{l}$ cDNAs was used for qPCR and the qPCR analysis was performed according to the standard protocol of the ABI 7500 system with SYBR Green supermix (Applied Biosystems; Thermo Fisher Scientific, Inc.). The reaction system (20 $\mu$ l) included $1 \mu \mathrm{l}$ cDNA, $2 \mu \mathrm{l}$ primer mix, $10 \mu \mathrm{l}$ SYBR green PCR

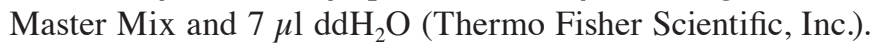
GAPDH was used as an internal control and the RT-qPCR analysis was repeated biologically three times with four technique repeats for each. The primers for were as follows: GAPDH, forward 5'-CTCCTGTTCGACAGTCAGCC-3' and reverse 5'-GCCCAATACGACCAAATCCG-3'; TET2, forward 5'-GCT AGGCTGCTTTCGTAGAG-3' and reverse 5'-GAATGTTTG CCAGCCTCGTTC-3'; ZEB1, forward 5'-AGCTGTTTCAAG ATGTTTCCTTCC-3' and reverse 5'-CCTATGCTCCACTCC TTGCT-3'. The PCR conditions were as follows: 1 cycle at $95^{\circ} \mathrm{C}$ for $5 \mathrm{~min} ; 40$ cycles at $95^{\circ} \mathrm{C}$ for $45 \mathrm{sec}, 61^{\circ} \mathrm{C}$ for $30 \mathrm{sec}$ and $72^{\circ} \mathrm{C}$ for $30 \mathrm{sec}$; and 1 cycle at $72^{\circ} \mathrm{C}$ for $10 \mathrm{~min}$. Cycle threshold values were established, and data were analyzed using $2^{-\Delta \Delta \mathrm{Cq}}$ method (19).

Immunohistochemistry. The tissue specimens were cut into 4- $\mu \mathrm{m}$ sections and the sections dried at $55^{\circ} \mathrm{C}$ for $2 \mathrm{~h}$, deparaffinized in xylene and rehydrated using a series of graded alcohol washes. The tissue slides were then treated with $3 \%$ hydrogen peroxide in methanol for 15 min to quench endogenous peroxidase activity, following which antigen retrieval was performed by incubation at $98-100^{\circ} \mathrm{C}$ for $10 \mathrm{~min}$ in $0.01 \mathrm{M}$ sodium citrate buffer $(\mathrm{pH} 6.0)$, heated using a microwave oven. Following preincubation for $1 \mathrm{~h}$ in $10 \%$ goat serum (Gibco; Thermo Fisher Scientific, Inc.), the specimens were incubated with the TET2 $(45010,1: 100)$ antibody and ZEB1 antibody (3396, 1:300) obtained from Cell Signaling Technology, Inc. (Danvers, MA, USA) for $1 \mathrm{~h}$ at room temperature. The tissue slides were treated with a non-biotin horseradish peroxidase detection system according to the manufacturer's protocol (Dako; Agilent Technologies, Inc., Santa Clara, CA, USA). The images were obtained using a light microscope (LEICA DM6000; Leica Microsystems GmbH, Wetzlar, Germany). Two pathologists evaluated the immunohistological samples and the intensity of immunostaining was considered when analyzing the data. The intensity of staining was scored (0-3) and the expression was classified as high if the score was $\geq 2$, and low if the score was $\leq 1$.

Western blot analysis. Total proteins were extracted from the corresponding cells using RIPA buffer (Thermo Fisher Scientific, Inc.) in the presence of a protease inhibitor cocktail (Thermo Fisher Scientific, Inc.). The protein concentrations of the lysates were measured using a BCA Protein Assay kit (Thermo Fisher Scientific, Inc.); $50 \mu \mathrm{g}$ protein was resolved and mixed with 5X Lane Marker Reducing Sample Buffer (Thermo Fisher Scientific, Inc.), electrophoresed on a $10 \%$ SDS-acrylamide gel and transferred onto an Immobilon-P Transfer Membrane (Merck KGaA, Darmstadt, Germany). The membranes were blocked with 5\% non-fat milk in Tris-buffered saline, following which they were incubated with primary antibodies at $4^{\circ} \mathrm{C}$ overnight, followed by a secondary antibody at room temperature for $2 \mathrm{~h}$. The signal was detected using an ECL detection system (Merck KGaA). The TET2 antibody (45010; 1:1,000), ZEB1 antibody $(3396 ; 1,000)$ and GAPDH antibody (2118; 1:1,000) were obtained from Cell Signaling Technology, Inc. The horseradish peroxidase-conjugated secondary antibody $(31460 ; 1: 20,000)$ was from Thermo Fisher Scientific, Inc.

Cell invasion assay. Invasion of the cells was assessed using a Cell Invasion Assay kit (BD Biosciences, Franklin Lakes, NJ, USA) according to the manufacturer's protocol. Briefly, at $36 \mathrm{~h}$ post-transfection, $3 \times 10^{4}$ cells in $300 \mu \mathrm{l}$ serum-free medium were added to the upper chamber precoated with ECMatrix ${ }^{\mathrm{TM}}$ gel. Subsequently, $0.5 \mathrm{ml}$ of $10 \%$ FBS-containing medium was added to the lower chamber as a chemoattractant. The cells were incubated for $24 \mathrm{~h}$ at $37^{\circ} \mathrm{C}$, following which the non-invading cells were removed with cotton swabs. The cells, which had migrated to the bottom of the membrane were fixed with pre-cooled methanol and stained with $2 \%$ Giemsa solution. The stained cells were visualized under a light microscope. To minimize bias, at least three randomly selected fields (magnification, $\mathrm{x} 100$ ) were counted, and the average number was determined.

Cell proliferation assay. Cell proliferation was monitored using an MTS assay with the CellTiter96 ${ }^{\circledR}$ AQueous One Solution Cell Proliferation Assay kit (Promega Corporation, Madison, WI, USA) according to the manufacturer's protocol. The cells were seeded into 96-well plates at 2,000 cells/well $(0.20 \mathrm{ml} /$ well $)$. The cell proliferation assay was performed 
on day 2 by incubation with MTS $(0.02 \mathrm{ml} /$ well $)$ at $37^{\circ} \mathrm{C}$ for $1 \mathrm{~h}$. Following incubation for a further $2 \mathrm{~h}$, the absorbance at $490 \mathrm{~nm}$ was recorded for each well on the BioTek Synergy 2 reader (BioTek Instruments, Inc., Winooski, VT, USA). The absorbance represented the cell number, with the absorbance of the control set as $100 \%$.

Xenograft model in nude mice. Xenograft tumors were generated by subcutaneous injection of U87MG/Control, U87MG/TET2, U251MG/Control and U251MG/TET2 cell lines at $2 \times 10^{6}$ cells in $200 \mu \mathrm{l}$, respectively, into the hind limbs of 4-6 week-old female Balb/C athymic nude mice, with three mice for each cell line. All mice were housed and maintained under specific pathogen-free conditions at $27^{\circ} \mathrm{C}$ with $12: 12 \mathrm{~h}$ light:dark cycle and fed with sterilized food and water, and all animal experiments were approved by the Experimental Animal Ethics Committee of Hubei University of Medicine and performed in accordance with institutional guidelines. Tumor growth was examined every 3 days during the animal experiment. The mice were sacrificed with $120 \mu 110 \%$ hydral (Sinopharm Chemical Reagent Co., Ltd, Shanghai, China) 27 days later and the tumors were harvested and weighed.

Chromatin immunoprecipitation (ChIP) assay. Using the high-quality transcription factor binding profile database (JASPAR database; http://jaspar.binf.ku.dk),ZEB1 was predicted for regulating TET2 transcription. To determine whether ZEB1 could bind to the TET2 promoter, the ChIP assay was applied in the present study. The ChIP assay was performed using an EZ-CHIP ${ }^{\mathrm{TM}}$ chromatin immunoprecipitation kit (Merck $\mathrm{KGaA}$ ). Briefly, chromatin proteins were cross-linked to DNA by the addition of formaldehyde to the culture medium to a final concentration of $1 \%$. Following incubation for $10 \mathrm{~min}$ at room temperature, the cells $\left(2 \times 10^{5}\right)$ were washed and scraped off in ice-cold phosphate-buffered saline containing Protease Inhibitor Cocktail II. The cells were pelleted and then re-suspended in lysis buffer containing Protease Inhibitor Cocktail II. The resulting lysate was subjected to sonication to reduce the size of DNA to $200-1,000$ base pairs in length. The sample was centrifuged at $10,000 \times \mathrm{g}$ at $4^{\circ} \mathrm{C}$ for $10 \mathrm{~min}$ to remove cell debris and diluted 10-fold in ChIP dilution buffer containing Protease Inhibitor Cocktail II. A $5 \mu \mathrm{l}$ sample of the supernatant was retained as 'Input' and stored at $4^{\circ} \mathrm{C}$. Subsequently $5 \mu \mathrm{g}$ of anti-RNA polymerase antibody (positive control, included in the kit), anti-ZEB1 antibody (Cell Signaling Technology, Inc.) or IgG (negative control) were added to the chromatin solution and incubated overnight at $4^{\circ} \mathrm{C}$ with rotation. Following antibody incubation, protein $\mathrm{G}$ agarose was added and the sample was incubated at $4^{\circ} \mathrm{C}$ with rotation for an additional $2 \mathrm{~h}$. The protein/DNA complexes were washed with wash buffers four times and eluted with ChIP elution buffer. Cross-links were then reversed to free DNA by the addition of $5 \mathrm{M} \mathrm{NaCl}$ and incubation at $65^{\circ} \mathrm{C}$ for $4 \mathrm{~h}$. The DNA was purified according to the manufacturer's protocol. A total of $50 \mu \mathrm{l}$ of DNA was obtained for each treatment, and $0.2 \mu \mathrm{l}$ of the DNA from each group was used as a template for PCR. The total $20 \mu \mathrm{l}$ reaction system include $0.2 \mu \mathrm{l}$ cDNA, $2 \mu \mathrm{l}$ primer mix, $10 \mu \mathrm{l}$ PCR Master Mix

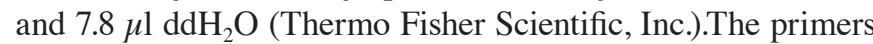
for the TET2 promoter containing putative ZEB1 binding sites were as follows: Sense 5'-GTGCATTAACAATTTCCAAGA
C-3' and antisense 5'-CAAAGTTGACTCAGATTTCAG-3'. Primers for the human GAPDH gene were as follows: Sense 5'-TACTAGCGGTTTTACGGGCG-3' and antisense 5'-TCG AACAGGAGGAGCAGAGAGCGA-3'. The PCR conditions were as follows: 1 cycle of $95^{\circ} \mathrm{C}$ for $5 \mathrm{~min} ; 32$ cycles of $95^{\circ} \mathrm{C}$ for $20 \mathrm{sec}, 59^{\circ} \mathrm{C}$ for $30 \mathrm{sec}, 72^{\circ} \mathrm{C}$ for $30 \mathrm{sec}$; and one cycle of $72^{\circ} \mathrm{C}$ for $10 \mathrm{~min}$. The PCR samples were resolved by electrophoresis on a $2 \%$ agarose gel and stained with ethidium bromide.

Promoter activity analysis. To determine whether ZEB1 regulated the promoter activity of TET2, a $2 \mathrm{~kb}$ region upstream of the first exon of TET2 was cloned into the pGL4-reporter vector upstream of the luciferase gene. The cells were seeded (1x10 $/$ well) in 96-well plates and co-transfected with the pGL4-reporter vector or pRL-TK Renilla luciferase vector, with or without the pSUPER-sh-ZEB1 vector, using Lipofectamine 2000 (Invitrogen; Thermo Fisher Scientific, Inc.). The transfection was performed at room temperature. After transfection, the cells were incubated at $37^{\circ} \mathrm{C}$ in cell culture conditions. After $48 \mathrm{~h}$, luciferase activity was determined using a Dual-Luciferase Reporter Assay system (Promega Corporation) on a BioTek Synergy 2 reader (BioTek Instruments, Inc.). The activity of Renilla luciferase was used as an internal control and firefly luciferase activity was calculated as the mean \pm standard deviation following normalization relative to the activity of Renilla luciferase.

Statistical analysis. All statistical analyses were performed using SPSS statistical software (version 21.0; IBM SPSS, Armonk, NY, USA). Survival curves were constructed using the Kaplan-Meier method and analyzed using the log-rank test. Significant prognostic factors identified by univariate analysis were entered into multivariate analysis using the Cox proportional hazards model. The results are reported as the mean \pm standard deviation. $\mathrm{P}<0.05$ was considered to indicate a statistically significant difference.

\section{Results}

Expression of TET2 is decreased in primary glioma tissues. To determine the role of TET2 in glioma, the present study measured the expression pattern of TET 2 in glioma tissues. RT-qPCR analysis was used to assess the mRNA levels of TET2 in tissues from 42 cases of primary glioma. Compared with matched non-tumor brain tissues, the mRNA levels of TET2 were significantly downregulated in the majority of primary glioma tissues, with a more marked decrease in high-grade gliomas, compared with low-grade gliomas (Fig. 1A). As survival data were not available for the tissues used for RT-qPCR analysis, another cohort of 96 tissues (comprising 11 normal brain tissues and 85 glioma tissues) with follow-up data were used to confirm the protein levels of TET2 via immunohistochemical staining. The protein levels of TET2 were lower in glioma tissues, compared with normal tissues (Fig. 1B). The downregulation of TET2 correlated with increases in tumor size and tumor grade (Table I). Of note, it was observed that lower expression levels of TET2 in patients with glioma were predictive of poorer overall survival rates (Fig. 1C). These results indicated that expression of TET2 was downregulated in gliomas. 
Table I. Analysis of the correlation between the expression levels of TET2 and ZEB1 with clinicopathological parameters in gliomas.

\begin{tabular}{|c|c|c|c|c|c|c|c|}
\hline \multirow[b]{2}{*}{ Parameter } & \multirow[b]{2}{*}{ Cases (n) } & \multicolumn{2}{|c|}{ TET2 } & \multirow[b]{2}{*}{ P-value } & \multicolumn{2}{|c|}{ ZEB1 } & \multirow[b]{2}{*}{ P-value } \\
\hline & & High & Low & & High & Low & \\
\hline Age & & & & 0.7143 & & & 0.5327 \\
\hline$<60$ years & 55 & 18 & 37 & & 31 & 24 & \\
\hline$\geq 60$ years & 30 & 11 & 19 & & 19 & 11 & \\
\hline Gender & & & & 0.6432 & & & 0.9586 \\
\hline Male & 41 & 15 & 26 & & 24 & 17 & \\
\hline Female & 44 & 14 & 30 & & 26 & 18 & \\
\hline Tumor size & & & & 0.0023 & & & 0.0380 \\
\hline$<4.5 \mathrm{~cm}$ & 42 & 21 & 21 & & 20 & 22 & \\
\hline$\geq 4.5 \mathrm{~cm}$ & 43 & 8 & 35 & & 30 & 13 & \\
\hline WHO grade & & & & 0.0004 & & & 0.0043 \\
\hline $\mathrm{I}+\mathrm{II}$ & $11+20$ & 18 & 13 & & 12 & 19 & \\
\hline III+IV & $21+33$ & 11 & 43 & & 38 & 16 & \\
\hline
\end{tabular}

TET2, ten-eleven translocation 2; ZEB1, zinc finger E-box-binding homeobox 1; WHO, World Health Organization.

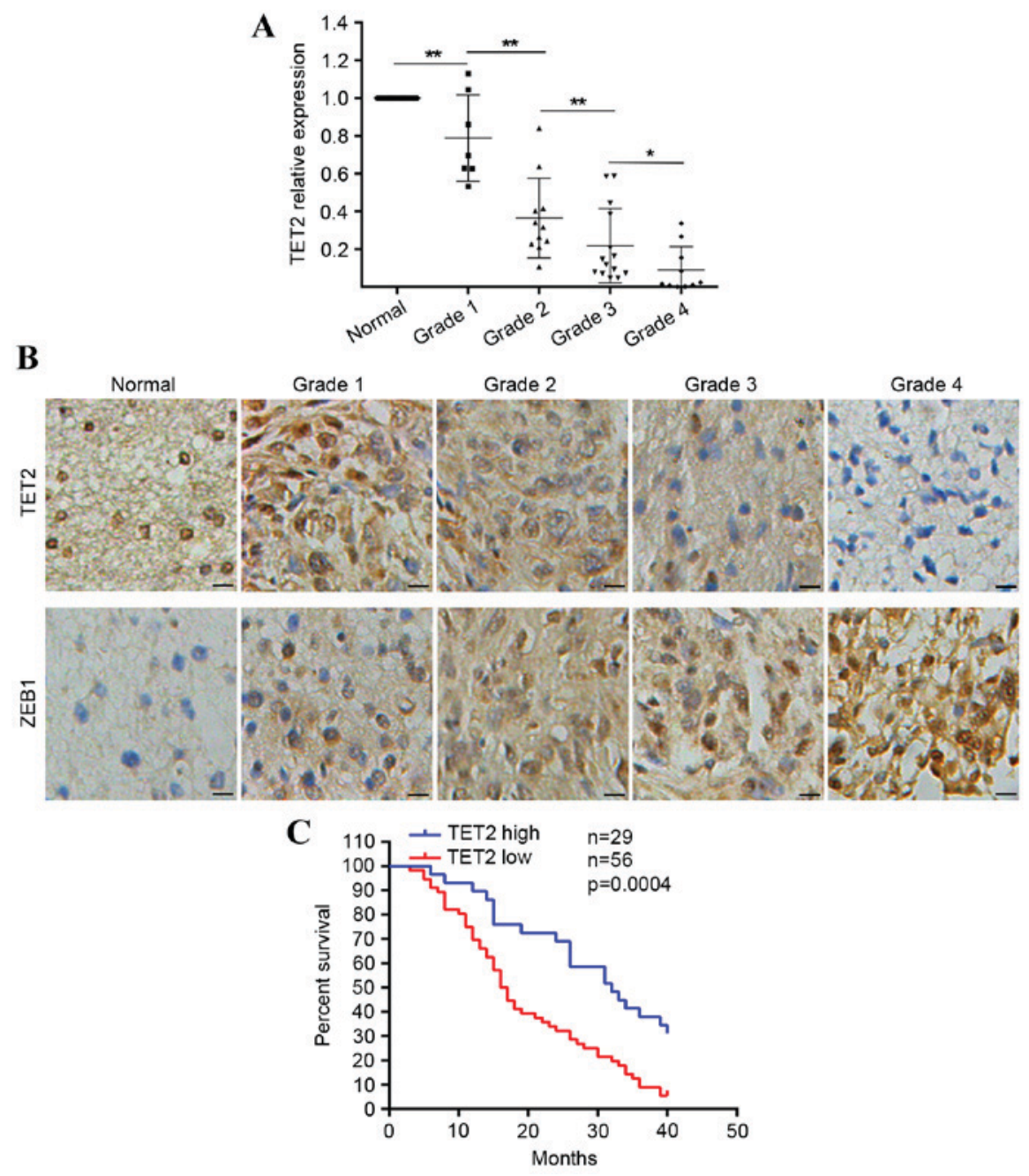

Figure 1. Expression of TET2 in gliomas. (A) Expression patterns of TET2 in human gliomas and their adjacent non-malignant brain tissues were detected using reverse transcription-quantitative polymerase chain reaction analysis. ${ }^{*} \mathrm{P}<0.05$ and ${ }^{* *} \mathrm{P}>0.01$. (B) Representative images of protein levels of TET2 and ZEB1 in glioma tissues detected using immunohistochemistry. Scale bar=50 $\mu \mathrm{m}$. (C) Kaplan-Meier analysis estimated the overall survival rates according to the protein level of TET2. TET2, ten-eleven translocation 2; ZEB1, Zinc finger E-box-binding homeobox 1. 
A

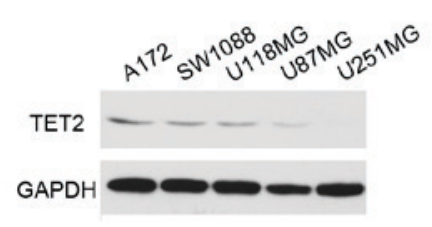

D
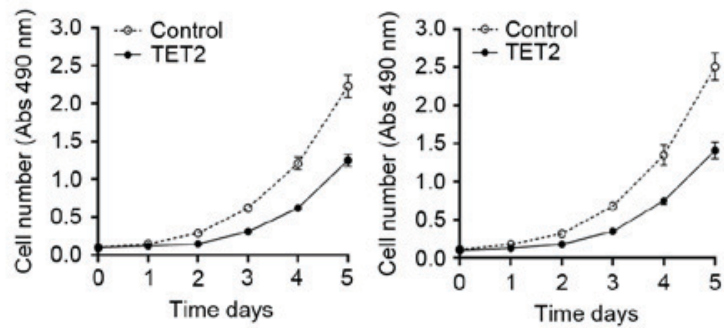

C

B

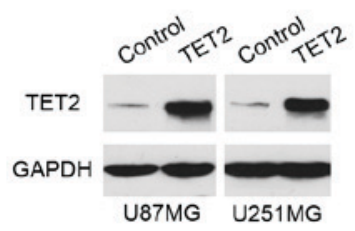

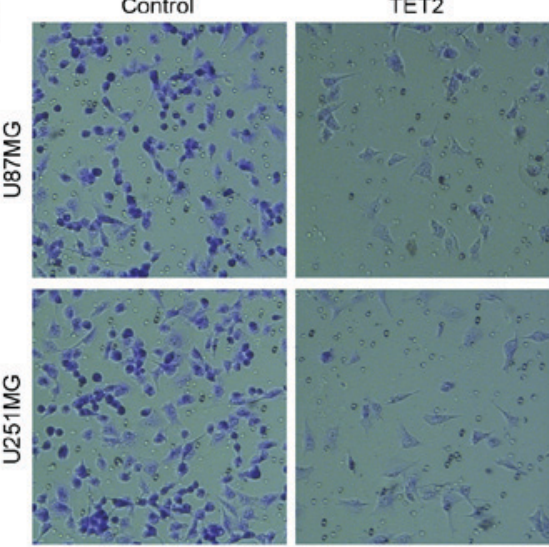

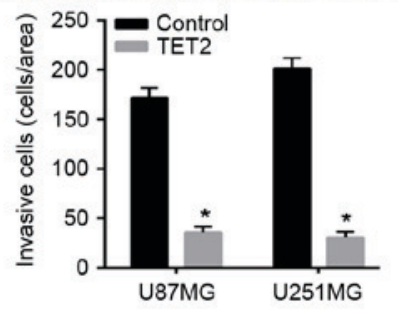

$\mathbf{E}$

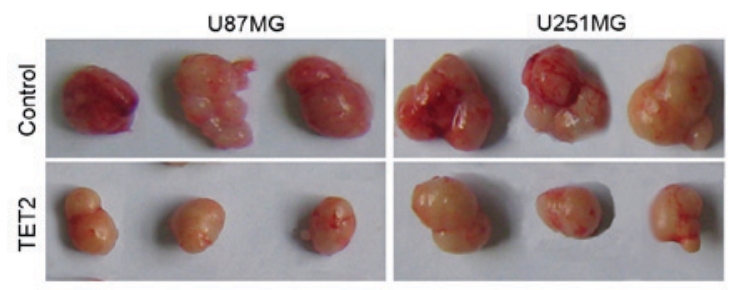

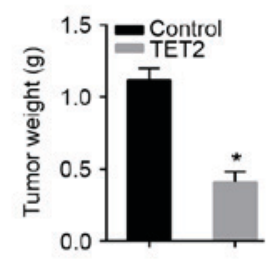
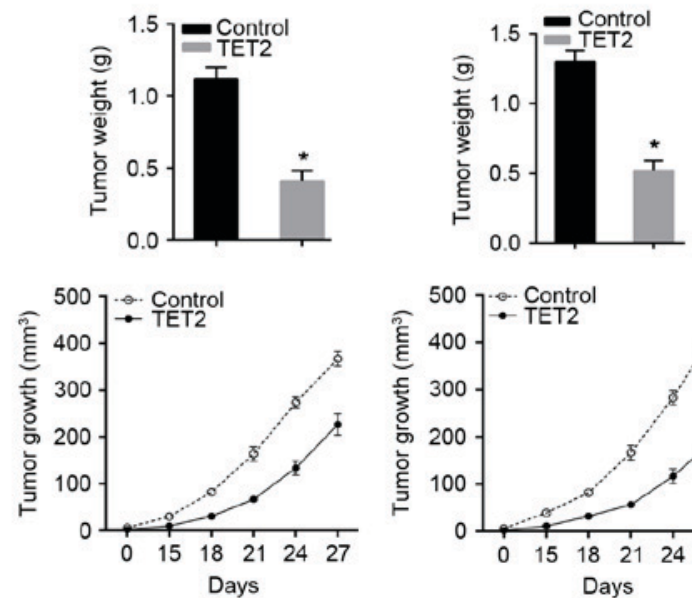

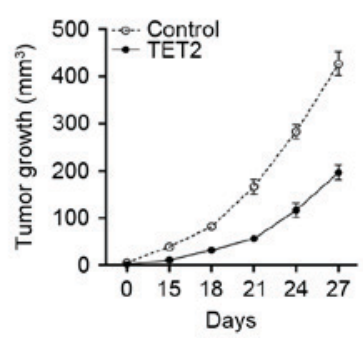

Figure 2. Effects to TET2 on the growth and invasion of glioma cells. (A) Western blot analysis showing baseline expression levels of TET2 in glioma cell lines. (B) Western blot analysis of protein expression levels of TET2 in U87MG and U251MG cell lines stably overexpressing TET2. (C) Overexpression of TET2 decreased invasion of U87MG and U251MG cells, as shown by cell counts per area. *P<0.01 vs. control. (D) TET2 inhibited U87MG and U251MG cell proliferation, determined using an MTS assay. (E) Tumor growth was monitored every 3 days. Tumor weight was recorded at the experimental endpoint. Data are presented as the mean \pm standard deviation from three mice. ${ }^{*} \mathrm{P}<0.01$ vs. control. TET2, ten-eleven translocation 2 .

TET2 inhibits glioma cell invasion and growth. To examine the functional role of TET2 in gliomas, the present study evaluated the protein level of TET2 in various glioma cell lines. It was found that TET2 was expressed at low levels in the A172, SW1088, U118MG, U87MG and U251MG glioma cell lines, compared with the endogenous control, GAPDH (Fig. 2A). U87MG and U251MG were used for overexpression of TET2 to investigate the biological role of TET2 in glioma cells (Fig. 2B). The results indicated that the overexpression of TET2 inhibited the invasion potential of the U87MG and U251MG cell lines (Fig. 2C). Additionally, it was found that TET2 induced marked growth inhibition in the U87MG and U251MG cell lines in vitro (Fig. 2D). The effect of TET2 on growth in glioma was further confirmed in nude mice with human glioma xenografts. This involved subcutaneous injection into the armpit of athymic mice with
TET2-overexpressing U87MG and U251MG cell lines and their associated control cell lines. As shown, the tumor sizes derived from the TET2-overexpressing U87MG and U251MG cell lines were significantly reduced (Fig. 2E). These results indicated that restoration of the expression of TET2 inhibited cell invasion and growth in glioma cells.

Expression of ZEB1 is inversely correlated with the expression of TET2. To determine whether transcriptional regulation contributed to the downregulation of TET2, the present study analyzed the response elements of a cohort of transcription factors located within a $2 \mathrm{~kb}$ region upstream of the first exon of the TET2 gene. Using the JASPAR database, a putative ZEB1 binding site (CACCTG) was identified within this region (Fig. 3A), suggesting that the overexpression of ZEB1 resulted in the repression of TET2. As expected, in the 42 primary 


\begin{tabular}{|l|l|l|l|l|l|}
\hline Model ID & Model name & Score & Start & End & Predicted site sequence \\
\hline MA0103.2 & ZEB1 & 11.009 & 786 & 794 & Tcccacctg \\
\hline
\end{tabular}
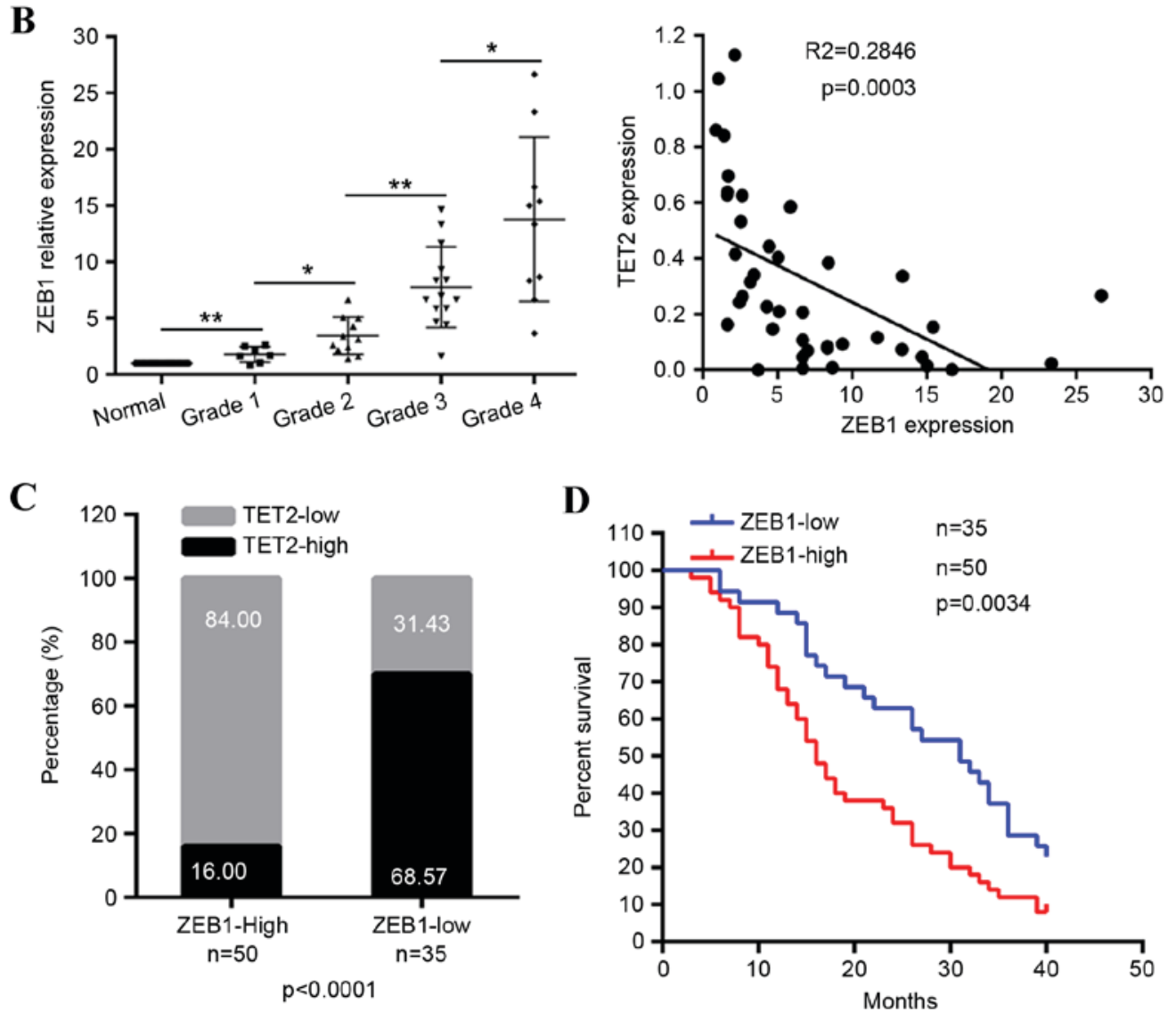

Figure 3. Expression of ZEB1 is inversely correlated with expression of TET2 in glioma. (A) Schematic representation of ZEB1 binding sites in the $2 \mathrm{~kb}$ putative TET2 promoter. The first base of the $2 \mathrm{~kb}$ strand is defined as ' 1 '. (B) Expression patterns of ZEB1 in human gliomas and their adjacent non-malignant brain tissues, detected using reverse transcription-quantitative polymerase chain reaction analysis. Pearson's correlation analyses between relative expression of ZEB1 and mRNA levels of TET2 in primary glioma tissues are shown. ${ }^{*} \mathrm{P}<0.05$ and ${ }^{* *} \mathrm{P}<0.01$. (C) Protein levels of TET2 in glioma exhibiting different protein expression levels of ZEB1. (D) Kaplan-Meier analysis estimated the overall survival rates according to the protein level of ZEB1. TET2, ten-eleven translocation 2; ZEB1, Zinc finger E-box-binding homeobox 1.

glioma tissue samples, compared with the matched non-tumor brain tissues, the mRNA levels of ZEB1 were significantly upregulated in the majority of primary glioma tissues, with a more marked increase in high-grade gliomas, compared with low-grade gliomas (Fig. 3B). The mRNA levels of ZEB1 were inversely correlated with the mRNA levels of TET2 (Fig. 3B). The protein levels of ZEB1 were also confirmed via immunohistochemical staining of the 96 tissues in which the protein levels of TET2 were measured. Compared with normal tissues, the protein levels of ZEB1 were high in glioma tissues (Fig. 1B) and negatively correlated with the expression of TET2 (Fig. 3C). The upregulation of ZEB1 was correlated with increases in tumor size and tumor grade (Table I), and were predictive of a poorer overall survival rate (Fig. 3D). These findings indicated a negative correlation between ZEB1 and TET2 in gliomas.

ZEB1 transcriptionally inhibits the expression of TET2 in glioma cells. As the expression of ZEB1 was inversely correlated with that of TET2 in gliomas, and there was a potential ZEB1 binding site in the TET2 potential promoter, it was necessary to verify whether ZEB1 transcriptionally regulated the expression of TET2 in gliomas. ZEB1 was expressed at high levels in the selected glioma cell lines (Fig. 4A). It was found that ZEB1-knockdown significantly upregulated the expression levels of TET2 in the U87MG and U251MG cell lines (Fig. 4B). To confirm the direct association of ZEB1 with the TET2 promoter, ChIP assays were performed in the U87MG and U251MG cell lines, which revealed that ZEB1 was bound to the TET2 promoter (Fig. 4C). To determine whether the $2 \mathrm{~kb}$ region had promoter activity, the $2 \mathrm{~kb}$ DNA was cloned into the pGL4 reporter plasmid. The experimental results indicated that luciferase activity driven by the potential TET2 promoter was lower in the U87MG and U251MG cell lines, compared with the control (Fig. 4C). However, ZEB1-knockdown enhanced the luciferase activity in the U87MG and U251MG cell lines (Fig. 4D). These results demonstrated that ZEB1 was able 
A

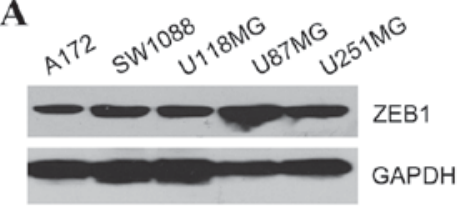

C

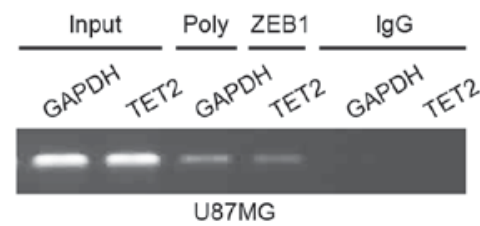

D

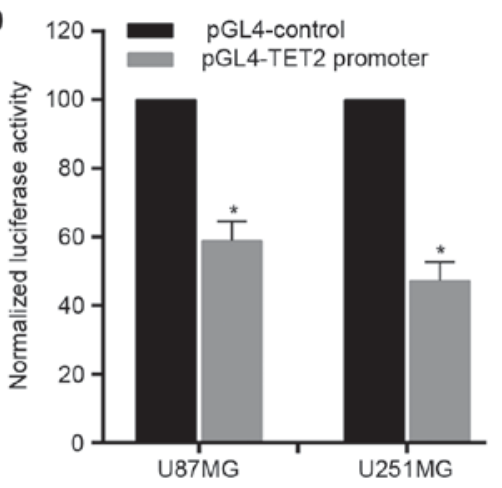

B

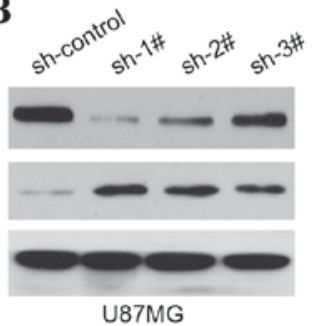

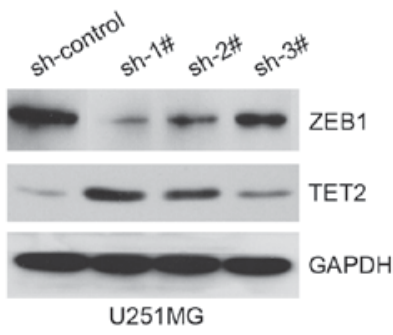

U251MG

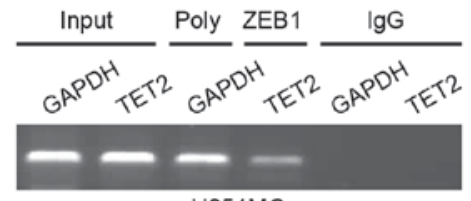

U251MG

E

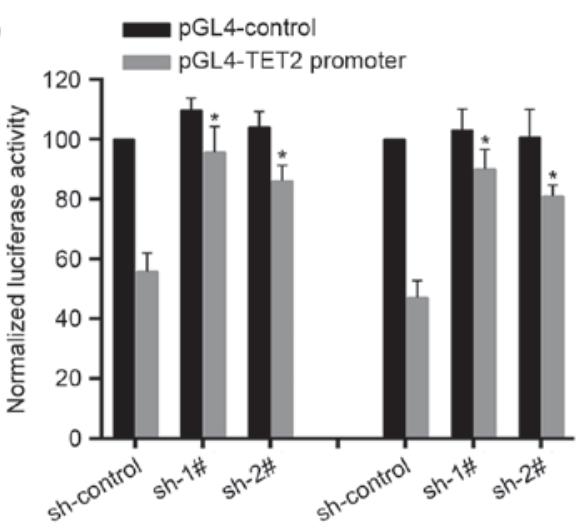

Figure 4. TET2 is downregulated by ZEB1 in glioma cells. (A) Western blot analysis showing baseline expression levels of ZEB1 in glioma cell lines. (B) Western blot analysis of protein expression levels of TET2 in U87MG and U251MG cell lines following ZEB1 knockdown. (C) Chromatin immunoprecipitation assays identified the ZEB1 binding site within the putative TET2 promoter. Primers specific for the binding site yielded PCR reaction products from ZEB1-DNA immunoprecipitates. The input represents DNA directly following lysis. The PCR reaction products for immunoprecipitates obtained using the RNA polymerase antibody and $\mathrm{IgG}$ represent the positive control and negative control. (D) Luciferase activity driven by the putative TET2 promoter was lower in the U87MG and U251MG cell lines, compared with the control construct ("P<0.001). (E) Reporter assays revealed altered luciferase activity following ZEB1 knockdown in U87MG and U251MG cell lines. "P<0.01 vs. sh control. TET2, ten-eleven translocation 2; ZEB1, Zinc finger E-box-binding homeobox 1; IgG, immunoglobulin G; sh, short hairpin RNA; poly, RNA polymerase.

to directly bind to the TET2 promoter to transcriptionally repress the expression of TET2 in glioma cells.

\section{Discussion}

Due to the poor prognosis of patients with malignant gliomas, there is an urgent requirement to examine the molecular mechanisms responsible for the progression of glioma. TET2 has been reported to act as a tumor suppressor in certain types of human cancer $(14,16)$, however, its role in glioma remains to be elucidated. In the present study, the expression pattern of TET2 in gliomas was determined. The findings indicated that TET2 was downregulated in gliomas and its downregulation was correlated with progression. Functionally, restoration of the expression of TET2 inhibited glioma cell growth and invasion, indicating that the repression of TET2 conferred the progression of gliomas.

TET1/2/3 promote DNA demethylation by catalyzing the conversion of $5 \mathrm{mC}$ primarily to $5 \mathrm{hmc}$, in addition to $5 \mathrm{fC}$ and $5 \mathrm{caC}(6,7)$. To date, the distinct function of $5 \mathrm{hmC}$ remains to be fully elucidated, however, there is evidence that $5 \mathrm{hmC}$, as an intermediate in active DNA demethylation, is involved in gene regulation, developmental control and malignant transformation $(20,21)$. Studies have revealed that TET2 mutations are accompanied by decreased levels of $5 \mathrm{hmC}$, particularly in hematopoietic diseases $(13,22,23)$. Human brain tissue exhibits high levels of $5 \mathrm{hmC}$, and there is loss of $5 \mathrm{hmC}$ in brain tumors leading to a disturbance of hydroxymethylome (24). However, in a previous study by Kraus et al (25) no correlation was found between alterations in TETs and the levels of $5 \mathrm{hmC}$ in gliomas. This suggests other disturbances, including disrupted gene expression or functional inhibition of TET proteins, may be responsible for the aberrant epigenome of gliomas. Consistently, the findings of the present study indicated that the expression of TET2 was significantly downregulated in gliomas. The roles of TET proteins in regulating chromatin architecture and gene transcription independently of DNA methylation have been gradually uncovered $(8,26)$. Thus, the precise molecular mechanisms underlying the effects of TET2 in gliomas require further examination and confirmation in future investigations.

The functional loss of TET2 due to mutations and/or deletions frequently occurs in hematopoietic diseases. As the expression of TET2 is repressed in gliomas, and the frequency of TET2 mutations (25) and methylation of the TET2 promoter are low (27), the present study focused on whether certain 
transcription factors can regulate the expression of TET2 in gliomas. ZEB1 was found to have an inverse correlation with levels of TET2 in gliomas. Bioinformatics analysis combined with experimental validation revealed that ZEB1 bound to the promoter of the TET2 gene and transcriptionally repressed its activity. ZEB1 has been reported to be expressed at high levels in epithelial cancer, and its expression correlates with poor prognosis (28). ZEB1 is an inducer of epithelial-to-mesenchymal transition via transcriptionally modulating the expression of cell adhesion molecules, microRNAs, particularly the miR-200 family, and cell polarity-associated genes, and then contributes to metastasis, drug resistance and poor clinical outcome $(29,30)$. Edwards et al (31) reported the induction of ZEB1 through the tumor microenvironment in glioma and the promotion of invasion. Siebzehnrubl et al (32) also showed the link between the ZEB1 pathway and glioblastoma initiation, invasion and chemoresistance, predicting shorter survival rates. Despite these reports on ZEB1 in glioma, further elucidation is required. The present study demonstrated that the overexpression of ZEB1 in glioma confers the downregulation of TET2, suggesting a novel mechanism for ZEB1 in the progression of glioma.

Taken together, the results of the present study demonstrated the expression pattern of TET 2 in glioma, and established TET2 as a regulator of growth and invasion. The elucidation of the ZEB1-TET2 axis provides novel insights into the molecular mechanisms underlying the progression of glioma and provides a rationale for the development of clinical anticancer intervention strategies targeting the ZEB1-TET2 axis.

\section{References}

1. Ohgaki $\mathrm{H}$ and Kleihues P: The definition of primary and secondary glioblastoma. Clin Cancer Res 19: 764-772, 2013.

2. Huse JT and Holland EC: Targeting brain cancer: Advances in the molecular pathology of malignant glioma and medulloblastoma. Nat Rev Cancer 10: 319-331, 2010.

3. Wen PY and Kesari S: Malignant gliomas in adults. N Engl J Med 359: 492-507, 2008

4. Lee KH, Ahn EJ, Oh SJ, Kim O, Joo YE, Bae JA, Yoon S, Ryu HH, Jung S, Kim KK, et al: KITENIN promotes glioma invasiveness and progression, associated with the induction of EMT and stemness markers. Oncotarget 6: 3240-3253, 2015.

5. Tahiliani M, Koh KP, Shen Y,Pastor WA, Bandukwala H, Brudno Y, Agarwal S, Iyer LM, Liu DR, Aravind L and Rao A: Conversion of 5-methylcytosine to 5-hydroxymethylcytosine in mammalian DNA by MLL partner TET1. Science 324: 930-935, 2009.

6. He YF, Li BZ, Li Z, Liu P, Wang Y, Tang Q, Ding J, Jia Y, Chen Z, Li L, et al: Tet-mediated formation of 5-carboxylcytosine and its excision by TDG in mammalian DNA. Science 333: 1303-1307, 2011.

7. Ito S, Shen L, Dai Q, Wu SC, Collins LB, Swenberg JA, He C and Zhang Y: Tet proteins can convert 5-methylcytosine to 5-formylcytosine and 5-carboxylcytosine. Science 333: 1300-1303, 2011.

8. Pastor WA, Aravind L and Rao A: TETonic shift: Biological roles of TET proteins in DNA demethylation and transcription. Nat Rev Mol Cell Biol 14: 341-356, 2013.

9. Dawlaty MM, Breiling A, Le T, Raddatz G, Barrasa MI, Cheng AW, Gao Q, Powell BE, Li Z, Xu M, et al: Combined deficiency of Tet1 and Tet2 causes epigenetic abnormalities but is compatible with postnatal development. Dev Cell 24: 310-323, 2013.

10. Ko M, Bandukwala HS, An J, Lamperti ED, Thompson EC, Hastie R, Tsangaratou A, Rajewsky K, Koralov SB and Rao A: Ten-Eleven-Translocation 2 (TET2) negatively regulates homeostasis and differentiation of hematopoietic stem cells in mice. Proc Natl Acad Sci USA 108: 14566-14571, 2011.

11. Costa Y, Ding J, Theunissen TW, Faiola F, Hore TA, Shliaha PV, Fidalgo M, Saunders A, Lawrence M, Dietmann S, et al: NANOG-dependent function of TET1 and TET2 in establishment of pluripotency. Nature 495: 370-374, 2013.
12. Quivoron C, Couronné L, Della Valle V, Lopez CK, Plo I, Wagner-Ballon O, Do Cruzeiro M, Delhommeau F, Arnulf B, Stern MH, et al: TET2 inactivation results in pleiotropic hematopoietic abnormalities in mouse and is a recurrent event during human lymphomagenesis. Cancer Cell 20: 25-38, 2011.

13. Delhommeau F, Dupont S, Della Valle V, James C, Trannoy S, Massé A, Kosmider O, Le Couedic JP, Robert F, Alberdi A, et al: Mutation in TET2 in myeloid cancers. N Engl J Med 360: 2289-2301, 2009.

14. Wang Y, Xiao M, Chen X, Chen L, Xu Y, Lv L, Wang P, Yang H, Ma S, Lin H, et al: WT1 recruits TET2 to regulate its target gene expression and suppress leukemia cell proliferation. Mol Cell 57: 662-673, 2015.

15. Zhao Z, Chen L, Dawlaty MM, Pan F, Weeks O, Zhou Y, Cao Z, Shi H, Wang J, Lin L, et al: Combined Loss of Tet1 and Tet2 Promotes B Cell, but Not Myeloid Malignancies, in Mice. Cell Rep 13: 1692-1704, 2015

16. Takayama K, Misawa A, Suzuki T, Takagi K, Hayashizaki Y, Fujimura T, Homma Y, Takahashi S, Urano T and Inoue S: TET2 repression by androgen hormone regulates global hydroxymethylation status and prostate cancer progression. Nat Commun 6: 8219, 2015.

17. Dzitoyeva $\mathrm{S}$, Chen $\mathrm{H}$ and Manev $\mathrm{H}$ : Effect of aging on 5-hydroxymethylcytosine in brain mitochondria. Neurobiol Aging 33: 2881-2891, 2012.

18. Hahn MA, Qiu R, Wu X, Li AX, Zhang H, Wang J, Jui J, Jin SG, Jiang Y, Pfeifer GP and Lu Q: Dynamics of 5-hydroxymethylcytosine and chromatin marks in Mammalian neurogenesis. Cell Rep 3: 291-300, 2013.

19. Livak KJ and Schmittgen TD: Analysis of relative gene expression data using real-time quantitative PCR and the 2(-Delta Delta C(T)) Method. Methods 25: 402-408, 2001.

20. Branco MR, Ficz G and Reik W: Uncovering the role of 5-hydroxymethylcytosine in the epigenome. Nat Rev Genet 13: 7-13, 2011.

21. Spruijt CG, Gnerlich F, Smits AH, Pfaffeneder T, Jansen PW, Bauer C, Münzel M, Wagner M, Müller M, Khan F, et al: Dynamic readers for 5-(hydroxy)methylcytosine and its oxidized derivatives. Cell 152: 1146-1159, 2013.

22. Ko M, Huang Y, Jankowska AM, Pape UJ, Tahiliani M, Bandukwala HS, An J, Lamperti ED, Koh KP, Ganetzky R, et al: Impaired hydroxylation of 5-methylcytosine in myeloid cancers with mutant TET2. Nature 468: 839-843, 2010.

23. Solary E, Bernard OA, Tefferi A, Fuks F and Vainchenker W: The Ten-Eleven Translocation-2 (TET2) gene in hematopoiesis and hematopoietic diseases. Leukemia 28: 485-496, 2014.

24. Kraus TF, Globisch D, Wagner M, Eigenbrod S, Widmann D, Münzel M, Müller M, Pfaffeneder T, Hackner B, Feiden W, et al: Low values of 5-hydroxymethylcytosine $(5 \mathrm{hmC})$, the "sixth base,' are associated with anaplasia in human brain tumors. Int J Cancer 131: 1577-1590, 2012.

25. Kraus TF, Greiner A, Steinmaurer M, Dietinger V, Guibourt V and Kretzschmar HA: Genetic characterization of ten-eleven-translocation methylcytosine dioxygenase alterations in human glioma. J Cancer 6: 832-842, 2015.

26. Zhang Q, Zhao K, Shen Q, Han Y, Gu Y, Li X, Zhao D, Liu Y, Wang $\mathrm{C}$, Zhang $\mathrm{X}$, et al: Tet2 is required to resolve inflammation by recruiting Hdac 2 to specifically repress IL-6. Nature 525 : 389-393, 2015.

27. Kim YH, Pierscianek D, Mittelbronn M, Vital A, Mariani L, Hasselblatt $\mathrm{M}$ and Ohgaki $\mathrm{H}$ : TET2 promoter methylation in low-grade diffuse gliomas lacking IDH1/2 mutations. J Clin Pathol 64: 850-852, 2011.

28. SchmalhoferO, Brabletz S and Brabletz T: E-cadherin, beta-catenin, and ZEB1 in malignant progression of cancer. Cancer Metastasis Rev 28: 151-166, 2009.

29. Wellner U, Schubert J, Burk UC, Schmalhofer O, Zhu F, Sonntag A, Waldvogel B, Vannier C, Darling D, zur Hausen A, et al: The EMT-activator ZEB1 promotes tumorigenicity by repressing stemness-inhibiting microRNAs. Nat Cell Biol 11: 1487-1495, 2009.

30. Zhang P, Sun Y and Ma L: ZEB1: At the crossroads of epithelial-mesenchymal transition, metastasis and therapy resistance. Cell Cycle 14: 481-487, 2015.

31. Edwards LA, Woolard K, Son MJ, Li A, Lee J, Ene C, Mantey SA, Maric D, Song H, Belova G, et al: Effect of brain- and tumor-derived connective tissue growth factor on glioma invasion. J Natl Cancer Inst 103: 1162-1178, 2011.

32. Siebzehnrubl FA, Silver DJ, Tugertimur B, Deleyrolle LP, SiebzehnrublD, Sarkisian MR, Devers KG, Yachnis AT, Kupper MD, Neal D, et al: The ZEB1 pathway links glioblastoma initiation, invasion and chemoresistance. EMBO Mol Med 5: 1196-1212, 2013. 